\section{Response to the 2014 Malcolm Pendlebury lecture}

R. Vasant ${ }^{1,2}$

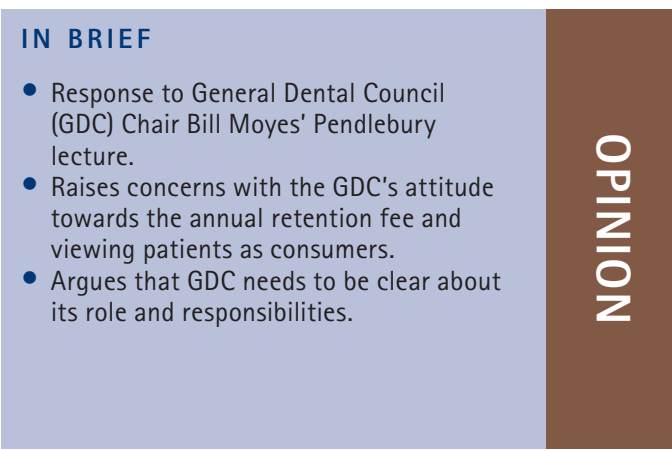

\begin{abstract}
On 12 June, General Dental Council Chair, Bill Moyes addressed the Faculty of General Dental Practice (UK) at its Malcolm Pendlebury lecture. Its contents have been subject to scrutiny, following the proposed substantial increase of the annual retention fee (ARF) and advertisements encouraging patient complaints. This article seeks to address concerns regarding the GDC's role and responsibilities.
\end{abstract}

Having read the transcript of Bill Moyes' recent Pendlebury Lecture $^{1}$ with great interest, several themes caught my eye:

\section{CHOICES IN HEALTHCARE}

Mr Moyes mentioned the importance of "customers' of healthcare services being able to, 'make rational choices, based on reliable information about the quality of performance of different providers. ${ }^{1}$ One of the pieces of the information jigsaw ought to be hard-earned, postgraduate qualifications.

I understand Mr Moyes is relatively new to dentistry. If he were to look through the history books, he will see that approved additional qualifications used to be published alongside registrants' names in the General Dental Council (GDC) register, until the (as yet unpublished) change in stance in October 2007. ${ }^{2}$ This was despite protests by many within the profession at the time, which appeared to fall on deaf ears within the GDC that this was removing a valuable information resource for patients. I feel that this has been forgotten by many. Is it now time, with a new council and chair, to accept some responsibility for the current situation and revise the current GDC stance? It is worth remembering that the approved qualifications were generally from institutions, principally the royal colleges and

\footnotetext{
Specialist Prosthodontist, M K Vasant \&t Associates, 1210 London Road, London, SW16 4DN; ${ }^{2}$ Senior Clinical Teaching Fellow, UCL Eastman Dental Institute, Continuing Professional Development, 123 Gray's Inn Road, London, WC1X 8WD

Correspondence to: Ronuk Vasant

Email:ronuk_vasant@hotmail.com
}

\section{Refereed Paper}

Accepted 27 July 2014

DOI: 10.1038/sj.bdj.2014.700

${ }^{\circ}$ British Dental Journal 2014; 217: 169-170 universities, which had their own, robust quality assurance mechanisms, many of which are respected globally.

Removing the registration of approved additional qualifications, created a more open and competitive educational market, which may be music to Mr Moyes' ears, given his background with the Office of Fair Trading (OFT). A 'Lidl to Waitrose' model, ${ }^{3}$ one could say, perhaps. Unfortunately, it has also meant the dilution of attendees across many more providers than were previously available. This has made it increasingly difficult for quality to improve or even be maintained, due to cost-cutting pressures and lack of income predictability. It has also reduced the incentive for dentists to pursue rigorous, demanding courses where there is a risk of personal failure, as the previous reward of a registrable qualification has been removed by the GDC. Again, this point has been made numerous times by individual and corporate respondents to GDC consultations. In other words, the competitive postgraduate education market has in some cases, produced a race to the bottom, for example with a discounting of ill-defined terms such as 'certificate' and 'diploma'. Unfortunately, the GDC position combined with the changes in university funding over the years, have together created a discounting pressure on what constitutes a 'Masters' degree amongst university providers also. My personal view is that public protection is not served by dentists' (understandable) pursuit of 'discounted' qualifications. It would be a very rare member of the lay public who would be prepared to spend the time and energy required to research the differences in postgraduate Master's degrees, even if sufficient information was available in a meaningful format. Herein lies a flaw in Mr Moyes' view, that if 'customers' have reliable information that they will make rational decisions. I feel that this is an overly simplistic and idealistic view of how 'customers' make decisions; particularly with a personal service such as dentistry, which is fundamentally different to retail.

Dentists being encouraged to pursue and invest in their own postgraduate education, often coming at huge personal expense and inconvenience, is a good thing from the point of view of patient protection, for several reasons that ought to be clear to any $B D J$ reader, as well as, I hope, Mr Moyes.

Mr Moyes returned to a similar theme later in the lecture. One of the pieces of information that patients have very poor knowledge of is the existence of specialist lists. Surely, if he is serious about 'customers' having the best information to help them make decisions about who they want treating them, raising the public awareness of these should be given a lot more priority by the GDC? The GDC has done very little, if anything, to promote the existence and understanding of specialist lists by the public since their inception in 1998. It may prove to be a very wise investment of annual retention fee (ARF) monies in reducing fitness to practise activity, if patients actively sought out specialist clinicians for aspects of their dental care.

Again, the needs of privately-owned businesses to make a profit ought to be very well understood. In times of rising professional and business costs, falling dentists' incomes and an ever-increasing supply of dental labour due to both immigration and direct access, there are clear disincentives for an enthusiastic practitioner 
to refer patients who present with problems at the edge of their experience levels.

\section{CUSTOMERS, NOT CLIENTS, OR, INDEED, PATIENTS}

Mr Moyes went on to state that, 'dentists and dental care professionals now have customers, not clients, or, indeed, patients.' ${ }^{1}$ If the GDC Chair believes that that is the case, then why is Standards for the dental team littered with the term 'patient'? Presumably, we can expect this and other GDC documents to be amended in the near future? Given that this would incur further costs, would such changes represent a good use of precious funds?

\section{GDC ROLE AND RESPONSIBILITIES}

He mentions, "the GDC needs to be clear about its role and responsibilities, although these are nowhere defined very clearly as far as I can establish. ${ }^{1}$ This comment is regrettable. Might I be so bold as to point Mr Moyes towards Part I, Section I of the Dentists Act 1984, where the "Constitution and general duties of the Council' are laid out quite clearly? Further details are given in Schedule I, Part I of the same Act. Either Mr Moyes is unfamiliar with the existence of the text, or feels that the wording of the Act is not sufficiently clear and open to interpretation. Some will find this amusing, given the ever increasing mountain of guidance, diktats, and laws that registrants must be familiar with and interpret. These come from various bodies for example, NHS contracts, GDC guidance, indemnity organisation guidance, professional body guidance, Health and Safety Executive (HSE) etc. In a GDC hearing, it would not be acceptable for a registrant to use a defence of ignorance, and his/her interpretation would be open to scrutiny and cross-examination by GDC counsel.

\section{HIGH-QUALITY CARE}

Mr Moyes went on to outline his current view of the GDC's roles and responsibilities. These included, 'to enable patients to secure high-quality care and effective treatment at a fair cost.'. I feel that this requires further, urgent explanation from Mr Moyes as to where he feels this extra remit comes from, as it appears to be a clear departure from the general duties of the GDC, as outlined in the Dentists Act 1984. Readers of the BDJ will immediately understand the enormity of the GDC concerning itself simultaneously with issues of cost in dentistry, as well as patient protection.

\section{CONTINUED PROFESSIONAL DEVELOPMENT}

Mr Moyes also turned to the topic of CPD quality, and how the GDC may, 'develop a better means of identifying CPD products (sic) that will genuinely improve the quality of dental care' ${ }^{1}$ Again, I realise that Mr Moyes is new to dentistry, but it is astonishingly naive to think that the quality of CPD is the major factor in improving dental care. As an educator myself, I wish it was a major factor. However, wishing doesn't make it true. The reality is that good quality care, however it is defined, will cost more than poor quality care. Time and time again I hear the same comments about the costs of time, materials and equipment from postgraduate students, who are keen to improve their standards of care. The economics of general practice, particularly within the GDS, are a major, if not the major factor, in the quality of care, as a reasonable profit has to be made. I will not insult the readers of this Journal by expanding further on this point.

\section{CLAIMS MANAGEMENT}

Mr Moyes stated that that: 'we don't behave like a claims management company!' Within a few weeks of his speech, there was a GDCfunded, full page advertisement placed in the Saturday Telegraph on 5 July 2014 stating: 'Not completely happy with your private dental care? Don't keep quiet about it.' This type of aggressive language seems to me to be exactly the type of wording that a claims management company would use; so this is a worrying piece of judgement from the GDC Chair.

The 2007 Government White Paper Trust, assurance and safety stated; 'Professional regulation needs to sustain the confidence of both the public and the professions through demonstrable impartiality. ${ }^{4}$ In this vein, I feel that some explanation from Mr Moyes is required.

The GDC declined our offer inviting Mr Moyes to reply to this Opinion Article by Ronuk Vasant, preferring instead that we conducted an interview with the Chief Executive and Registrar, which will appear in a future issue.

1. Moyes W. Pendlebury lecture. London, Royal College of Surgeons of England: General Dental Council, 2014. Online lecture available at https://www. gdc-uk.org/Newsandpublications/viewfromthechair Documents/PENDLEBURY\%20LECTURE-William\%20 Moyes-June2014-FINAL.pdf (accessed July 2014).

2. General Dental Council. Item 5, Council minutes of 18 May 2010. London: GDC, 2010.

3. Ward P. Human beans. Br Dent J 2014; 216: 543.

4. Department of Health. Trust, assurance and safety: the regulation of health professionals in the 21st century. London: DH, 2007. Online article available at https://www.gov.uk/government/publications/ trust-assurance-and-safety-the-regulation-ofhealth-professionals-in-the-21st-century (accessed July 2014). 